\title{
Extra-articular tenodesis for anterior cruciate ligament rupture in amateur skiers
}

\author{
P. Neyret MD, J. R. Palomo MD, S. T. Donell FRCS(Orth) and H. Dejour MD \\ Department of Orthopaedics and Traumatology, Centre Hospitalier Lyon-Sud, France
}

\begin{abstract}
Thirty one amateur skiers with 33 knees which had had a symptomatic chronic rupture of the anterior cruciate ligament (ACL) treated with the Lemaire operation were reviewed retrospectively at an average of 4.5 years. Of the patients 23 were women. The operation failed to control symptoms in 17 out of the 33 knees. However the operation did control symptoms in 13 out of 19 knees in patients over 35 years old, compared with only three out of 14 knees in patients under 35 years old. Clinical and objective testing however showed that most knees were still unstable. Despite this 21 patients continued skiing. One patient with a successful result switched to playing tennis. Five patients gave up all sports. Four further patients, all under 35 years old, returned to skiing after an additional intra-articular reconstruction of the anterior cruciate ligament. An isolated extra-articular procedure in amateur skiers under 35 years old with symptomatic chronic ACL rupture is not recommended. They need at least an intra-articular reconstruction to control their symptoms and to stabilize the knee.
\end{abstract}

Keywords: Extra-articular tenodesis, anterior cruciate ligament deficiency, amateur skiers

Skiing is a popular winter sport and it has been noted that rupture of the anterior cruciate ligament $(\mathrm{ACL})$ is reaching epidemic proportions in skiers. There are, for instance, an average of four ruptures a day from the slopes of Aspen, Colorado, USA ${ }^{1}$. The most likely people to rupture their ACL are the occasional skiers on their late afternoon ski run when they are tired ${ }^{1,2}$.

Management of top level skiers has been reported $^{2-4}$. Higgins and Steadman ${ }^{4}$ reviewed 27 top-class professional skiers in whom they had performed an intra-articular ACL repair for acute rupture, with excellent results. They had had bad results with conservative management in this class of athlete. However the patients who present with a chronically ruptured ACL tend to be amateur rather than professional skiers.

Extra-articular operations for a ruptured ACL using a graft of fascia lata have been used for a long time ${ }^{5-7}$. We have used the Lemaire operation ${ }^{8,9}$ which routes a $16 \times 1.5-\mathrm{cm}$ strip of fascia lata that remains attached to Gerdy's tubercle under the lateral collateral

Address for correspondence: $\mathrm{Mr}$ S. T. Donell, Institute of Orthopaedics, Royal National Orthopaedic Hospital, Brockley Hill, Stanmore, Middlesex, HA7 4LP, UK

(C) 1994 Butterworth-Heinemann Ltd 0306-3674/94/010031-04 ligament and then through an osseous tunnel under the head of the lateral gastrocnemius muscle. It then passes back under the lateral collateral ligament and is attached to another osseous tunnel under Gerdy's tubercle. This operation has a reported success rate from $75 \%$ to $91 \%{ }^{10,11}$ although a review of sportsmen put the success rate at $42 \%$ to $51 \%{ }^{12,13}$.

This study reviews our experience using the Lemaire operation as the sole procedure to control instability from a chronically ruptured ACL in a group of amateur skiers.

\section{Material and methods}

Between June 1978 and June 1988, 93 patients, 27 of whom were women, underwent an isolated extraarticular Lemaire operation for rupture of the anterior cruciate ligament. Of these patients 34 were skiers. Three patients were lost to follow-up, two of them having gone abroad. Of the remaining 31 patients, two had bilateral injuries. There were therefore 33 knees in the study. Of the patients 23 were women and eight were men. Five patients (four women and one man) skied regularly in competitions, but were not professionals, 24 patients skied regularly but not in competitions, and two patients only skied occasionally for a holiday.

The mean age of the patients was 35 years old (range 15-56 years), the delay between injury and operation was 2.3 years (range 6 months to 11 years), and the average follow-up was 4.5 years (range 6 months to 11 years). There were 18 right knees treated and 15 left knees.

The sporting level and knee function were assessed using the Arpège system ${ }^{14-16}$. The competitive skiers were classed 'competitive' (C), the regular skiers were classed 'leisure' (L), and the occasional skiers were classed 'active' (A). The Arpège system scores knee function in three categories, each with a maximum of nine points, giving a maximum total of 27 points. The categories are stability, pain and endurance, and mobility. The numerical value given in the assessment depends on the sporting class that the patient has attained. A competitive or leisure patient will score nine for stability only when the knee is completely stable during sports, when the knee can be used normally in sports that involve pivoting and contact with other players (e.g. football), and when the patient can run and jump. The active patient however will score nine points if they can run and jump, walk normally on any ground, 
and can climb stairs normally. The Arpège functional assessment therefore has two elements, the sporting class, and the functional score, and the latter depends on the former.

A subjective assessment was also made by the patients with the categories: very satisfied, satisfied, disappointed, and dissatisfied.

The results of the affected knees were subdivided into two groups according to their results: those that were successful were called group 1 , and those that were failures were called group 2. Success was defined as a good or excellent functional result, with a good or average sporting class result, and also with the patients being subjectively satisfied or very satisfied. A failure was defined as all patients who were not a success and any patient who required a later intra-articular ACL reconstruction.

Six group 1 and nine group 2 knees had a partial medial meniscectomy at the time of the operation. One knee in group 1 had a medial meniscal suture. Two group 2 knees had had a previous partial medial meniscectomy. One knee in each group underwent a partial lateral meniscectomy. Eight successful knees and five of the failed knees had only the Lemaire operation performed with no operation on the meniscus (or previous meniscectomy).

Fifteen patients were reviewed clinically, of whom 12 were in the successful group. Information on the other 16 patients was taken from their notes and five of them were also contacted by telephone.

Clinical assessment of stability included the Lachman's test and the pivot shift. The radiological assessment consisted of a unilateral weight-bearing radiograph of both knees in both the frontal and sagittal planes ${ }^{17,18}$. The frontal (posteroanterior) view allows assessment of joint line changes, and the sagittal (lateral) allows assessment of any anterior tibial translation (subluxation). The difference in anterior translation between the affected and the normal knee is termed the anterior tibial translation difference (ATTdiff). This test was performed on 11 patients. Seven patients had a radiological Lachman's test $^{17}$ where a lateral radiograph of the knee is taken in $20^{\circ}$ flexion with the patient supine. The patient maintains this position with a $7-\mathrm{kg}$ weight hanging from the ankle. Comparison of the difference in translation with the normal knee being termed the radiological Lachman's test difference (LTdiff). This has recently been shown to correlate well with the results of the KT-1000 arthrometer ${ }^{19}$ (MedMetric, San Diego, California, USA).

Analysis of selected data was made using the SPSS/PC statistical package (SPSS, Chicago, Illinois, USA). The significance level selected was 0.05 .

\section{Results}

There were 16 knees in group 1 , and 17 knees in group 2. Four patients in group 2 had had a subsequent intra-articular modified Jones reconstruction of the ACL. The mean age of the successful (group 1) patients was 40 years old (range 18 to 55 ), and of the failures was 32 (range 15-56) years old ( $P$ $=0.023 ; F$ test). The mean follow-up was 6 (range 2 to 11) years for group 1, and 3 years (range 6 months to
8 years) for group $2(P=0.012 ; F$ test). The delay between injury and operation was 2.2 years (range 6 months to 5 years) for group 1 , and 2.4 years (range 7 months to 11 years) for group 2 .

\section{Age}

Analysis of the patients by age showed that 13 out of the 19 knees in patients over 35 years old were successful, and 11 out of the 14 knees in patients under 35 years old were failures $(P=0.008$; Pearson's $R)$. The three successful knees in the patients under 35 years old were: one in a woman aged 18 at the time of her operation who had a medial meniscal tear sutured; one in a woman aged 28; and the last in a man aged 23. Neither of the last two had a meniscal lesion. Of the younger patients with failed knees, and not including a girl aged 15 years who had an open physis, one had had previous medial meniscectomy, six underwent a medial meniscectomy at the time of their Lemaire operation, and one had a lateral meniscectomy. Only two patients did not have a meniscal lesion, a man aged 23 years old and a woman aged 28 years old.

\section{Sporting class}

The sporting class results in group 1 were good for 12 knees, average for three knees, and one was not classified as the patient had her result affected by her other knee. For group 2, eight knees were classed as good, three were average, and two were bad. This excluded four patients who had a subsequent intra-articular ACL reconstruction performed because of continuing symptoms. In group 1 all patients continued skiing except for one who changed to tennis. In group 2 five patients gave up all sports, the rest continued skiing, including those who had subsequent ACL reconstructions.

\section{Functional results}

In group 1 the total Arpège score changed from an average of 18.5 to 25.5 . In group 2 it changed from 18.5 to $22(P<0.001 ; F$ test). In group 1 all knees were perfectly stable functionally, whereas in group 2 only one knee was.

\section{Subjective results}

The subjective assessment of those patients who had only had a Lemaire operation to treat their ACL rupture was: six knees very satisfied; 10 knees satisfied; six knees disappointed; and seven knees dissatisfied. This excludes the four patients who underwent an intra-articular ACL reconstruction.

\section{Clinical stability}

All patients had a positive Lachman's test before their operation, as did all 17 patients where the Lachman test was noted after the operation. All patients had a preoperative positive pivot shift test. The postoperative pivot shift at 1 year was positive in four out of 11 successful knees, and five out of seven failures. At 
follow-up 12 of 15 knees had a positive pivot shift, being negative in three of the nine successful knees. All three successful patients under 35-years old had a positive pivot shift.

\section{Bilaterality}

One of the bilateral patients had both knees in group 1 , another patient had a knee in each group. Both were female. A further patient in group 1 sustained an ACL rupture in her opposite knee but declined to have this operated on. The girl aged 15-years old with open physes had had a subsequent bad result. She had an intra-articular ACL reconstruction on her opposite knee for a subsequent injury.

\section{Radiological assessment}

Four knees had radiological evidence of degenerative arthritis with joint space narrowing and subchondral sclerosis, one of which was being considered for a valgus tibial osteotomy. All four had clinical effusions (one other patient was noted to have an effusion at follow-up). Three were from group 2 and all had had a medial meniscectomy. Two knees had evidence of remodelling changes secondary to $\mathrm{ACL}$ rupture, but not definite osteoarthritis.

The mean (range) LTdiff at follow-up was 4 (0-8) $\mathrm{mm}$. The mean (range) ATTdiff was $3(0-8) \mathrm{mm}$. The four patients with osteoarthritis had a mean(range) ATTdiff of $6(5-8) \mathrm{mm}(P=0.016 ; F$ test $)$. This probability level should be treated with caution as the numbers are small.

\section{Discussion}

Many extra-articular operations using a fascia lata graft have been described to treat a ruptured $\mathrm{ACL}^{5-8,11,20,21}$. The reported general success rates vary from $57 \%$ good results with the Ellison procedure $7,75 \%$ to $91 \%$ with the Lemaire ${ }^{10,11}, 82 \%$ with the Losee ${ }^{22}, 74 \%$ with the MacIntosh ${ }^{23}$. However the results for sportsmen are not so encouraging with rates varying from $30 \%$ to $75 \%$ good $^{11-13,20,21,23,24}$. The main problem with the reported results is that they depend on the definition of success. On sporting class assessment, this study showed 26 of 33 knees were good or average $(79 \%)$. Twenty one of 31 patients $(68 \%)$ were able to return to skiing. Furthermore the results are likely to be even better in a predominantly non-sporting population. The curious finding is that despite having post-operative clinical instability almost the same as that before the operation some patients were still happy.

It is clear that some skiers do need an ACL to be able to ski comfortably. The results of Higgins and Steadman ${ }^{4}$ showed that, in professional skiers, an aggressive approach in patients who maximally load their knees had a high rate of success. The figures in this study of lesser athletes show that a less invasive operation does not have as good results and suggest that a more aggressive approach is also required for symptomatic amateur skiers. We have had an $83 \%$ success rate when a modified Jones intra-articular reconstruction has been performed in addition to the Lemaire in patients with chronically ruptured ACLs. In this series $88 \%$ were active in sports and $16 \%$ were skiers $^{16}$. This compares with a $21 \%$ success rate in the same aged patients in this study. Our overall results are similar to those reported by Burgot et al. ${ }^{12}$ using the same operation on a predominantly sporting population.

\section{Length of follow-up}

In our study, if only those patients followed up for longer than 1 year are assessed, then the success rate would have risen from $48 \%$ to $59 \%$. Our patient population is widespread with only about $40 \%$ being local. If the operation was not successful the patients tended to fail to attend the routine 1-year follow-up appointment, or the review clinic. In these patients dissatisfaction with the result was already noted.

\section{Age of patient}

The predominant factor that led to success or failure in this study was the age of the patient. This is probably because the older patient does not load the knee to the same extent as a younger patient. The operation worked reasonably well for patients over 35 years old (68\% successful), and badly for those under this age $(21 \%)$. This is exactly the opposite view to Kennedy et al. ${ }^{7}$ when reporting results of the Ellison procedure, and Saillant et al..$^{13}$ for the Lemaire, but agrees with Burgot et al. ${ }^{12}$ also with the Lemaire.

\section{Bad results}

Bad results have been reported to be associated with a number of factors:

1. Delay to surgery. There was no significant difference in the time taken to surgery from injury between our successful and unsuccessful patients, unlike other studies ${ }^{7,11,13}$ which showed that the longer the delay the worse the outcome.

2. Meniscectomy. Previous or peroperative meniscectomy, either on the lateral side ${ }^{10,13}$, or both medial and lateral ${ }^{11}$ have been implicated in bad results. The numbers in this study are small but they do show that the three successful patients under 35-years old had intact, or repaired menisci. Most of the patients had undergone meniscectomies on the medial side.

3. Instability. An extra-articular tenodesis is designed to control the pivot shift. It never controls anterior tibial translation in the sagittal plane. Therefore the patients will always have a positive Lachman test. Varying degrees of instability have been implicated as causing poor results, in particular a positive pivot shift ${ }^{12,13,20,23}$. This view was not confirmed by this study, but the numbers seen were small. In an operation that is designed to control the pivot shift the reported positive rate afterwards varies from 16 to $86 \%^{12,22-24}$. It seems likely that fascia lata stretches with time, and probably is one of the reasons why the operation fails in the young sporting patient, and that early poor results do not improve with time. 


\section{Arthritis}

Many studies have shown poor results correlating with the presence of pre-existing osteoarthritis or chondral damage $11,13,20,23$. Although pre-existing damage was not noted in this study, all the patients with osteoarthritis had had a medial meniscectomy and three of four had bad results. The correlation with the amount of anterior tibial translation is interesting as excessive anterior tibial translation seems to be the mechanism for later onset arthritis. For operations on a ruptured ACL to reduce the risk of osteoarthritis, this laxity needs to be control$\operatorname{led}^{25,26}$.

\section{Sex}

The skiers in this study were predominantly women. It is interesting to note that 24 of the 27 women who had the Lemaire performed for ruptured ACL were skiers. Top level women skiers have more injuries in general than men skiers and are thought to be at risk because of generalized laxity, and smaller muscle mass $^{2}$. However this was from a study of 91 skiers with 67 injuries of which only four were ACL ruptures. In another report from this centre reviewing top level skiers with a ruptured ACL, 10 were women and seven were men ${ }^{3}$. In the amateur skier one explanation might be that men cope well without an ACL, thus explaining the view that the ACL is not necessary for skiing. It is possible to ski without an $\mathrm{ACL}$, but that does not mean that the knee is sound.

It should be emphasized that the patients in this study were pre-selected since they were symptomatic, and that it has been reported that women patients usually have worse functional and subjective results after surgery than men ${ }^{24}$. This may have biased the results relative to other published work. However the results in this study are similar to those of a group comprising $80 \%$ men who were predominantly sportsmen $^{12}$.

Skiers with a ruptured ACL put more demands on their knees than nonsportsmen. Some of them suffer from symptoms of instability and pain when skiing. The Lemaire extra-articular fascia lata tenodesis abolished symptoms in $68 \%$ of patients over 35 -years old. However patients under 35-years old fared worse, especially if meniscectomy was required. Patients who were unhappy with their treatment failed to attend follow-up. Reporting only those followed-up, or those followed-up for over a year, will improve the apparent success rates for this operation. Extra-articular tenodesis alone is not a suitable operation for amateur skiers with a ruptured ACL.

\section{Acknowledgements}

The authors would like to thank Dr P. Adeleine of the Laboratoire d'Informatique Médicale des HCL for help with the statistical analysis.

Mr S. T. Donell's visit to the Centre Hospitalier was aided by a King's Fund Travelling Fellowship grant.

\section{References}

1 Feagin JA, Lambert KL, Cunningham RR et al. Consideration of the anterior cruciate ligament injury in skiing. Clin Orthop 1987; 216: 13-8.

2 Rioufrays M. Accidents traumatiques au sein des équipes de France de ski alpin. Saison 86/87. Thèse Med Lyon, 1988.

3 Grand P. Etudes du retentivement d'une intervention pour rupture du ligament croisé antérieur sur les performances des skiers de haut niveau. Thèse Med Lyon, 1987.

4 Higgins RW, Steadman JR. Anterior cruciate ligament repairs in world class skiers. Am J Sports Med 1987; 15: 439-47.

5 Bosworth DM, Bosworth BM. Use of fascia lata to stabilize the knee in cases of ruptured crucial ligaments. J Bone Joint Surg 1936; 18: 178-79.

6 Carrell WB. Use of fascia lata in knee-joint stability. J Bone Joint Surg 1937; 19: 1018-26.

7 Kennedy JC, Stewart R, Walker DM. Anterolateral rotatory instability of the knee joint. An early analysis of the Ellison procedure. I Bone Joint Surg [Am] 1978; 60-A: 1031-39.

8 Lemaire M. Rupture ancienne du ligament croisé antérieur du genou. J Chir (Paris) 1967; 93: 311-20.

9 Lemaire M, Combelles F. Technique actuelle de plastie ligamentaire pour rupture ancienne du ligament croisé antérieur. Rev Chir Orthop 1980; 66: 523-5.

10 Chassaing V. La ligamentoplastie palliative (technique Lemaire) pour rupture du ligament croisé antéro-externe. SOFCOT Réunion annuelle, nov 1979. Rev Chir Orthop 1979; 66(Suppl. 2): 93-6.

11 Lemaire M. Résultats de la plastie extra-articulaire palliative de la rupture du ligament croisé antérieur. Rev Chir Orthop 1983; 69: 278-82.

12 Burgot D, Rosset P, Favard L et al. Laxités chronique antérieures du genou traitées par ligamentoplastie extraarticulaire. 226 cas revus à plus de 2 ans. Rev Chir Orthop 1988; 74: 424-9.

13 Saillant G, Bouchet T, Salgado V et al. Cure chirurgicale des laxités chroniques antérieures du genou par la plastie extra-articulaire de Lemaire. Résultats à propos de 132 cas. I Traumatol Sport 1988; 5: 67-72.

14 Aubriot $\mathrm{JH}$. Evaluation fonctionelle des résultats de la chirurgie du genou. In: Cahiers d'Enseignement de la SOFCOT 23. Paris, France: Expansion Scientifique Française, 1987; 219-32.

15 Dejour $\mathrm{H}$. Les résultats du traitement des laxités du genou. Introduction, Symposium SOFCOT, Paris 1981. Rev Chir Orthop 1983; 69: 255-7.

16 Dejour H, Walch G, Neyret P, Adeleine P. Résultats des laxités chroniques antérieures opérées. A propos de 251 cas revus avec un recul minimum de 3 ans. Rev Chir Orthop 1988; 74: 622-36.

17 Dejour H, Walch G, Chambat P, Ranger P. Active subluxation in extension. Am J Knee Surg 1988; 1: ?04-11.

18 Rosenberg TD, Paulos LE, Parker RD, Loward DB, Scott SM. The forty-five degree posteroanterior flexion weight-bearing radiograph of the knee. J Bone Joint Surg [Am] 1988; 70-A: 1479-83.

19 Franklin JL, Rosenberg TD, Paulos LE, France EP. Radiographic assessment of instability of the knee due to rupture of the anterior cruciate ligament. A quadriceps contraction technique. J Bone Joint Surg [Am] 1991; 73-A: 365-72.

20 Amirault JD, Cameron JC, Macintosh DL, Marks P. Chronic anterior cruciate ligament deficiency. Long-term results of MacIntosh's lateral substitution reconstruction. J Bone Joint Surg $[B r]$ 1988; 70-B: 622-24.

21 Odensten M, Lysholm J, Gillquist J. Long-term study of a distal iliotibial band transfer (DIT) for anterolateral knee instability. Clin Orthop 1983; 176: 129-35.

22 Losee RE, Johnson TR, Southwick WO. Anterior subluxation of the lateral tibial plateau. J Bone Joint Surg [Am] 1978; 60-A: 1015-30.

23 Ireland J, Trickey EL. MacIntosh tenodesis for anterolateral instability of the knee. J Bone Joint Surg [Br] 1980; 62-B: 340-5.

24 Teitge RA, Indelicato PA, Kerlon R. Iliotibial band transfer for antero-lateral instability of the knee. Am J Sports Med 1980; 8: 223-7.

25 Dejour H, Walch G, Deschamps G, Chambat P. L'arthrose du genou dans les laxités chronique antérieures. Rev Chir Orthop 1987; 73: 157-70.

26 Dejour $H$, Neyret $P$. Der Einbeinstand bei Chronischer Knieinstabilität. In: Jakob RP, Stäubli H-V, eds. Kniegelenk und Kruezbänder. Berlin, Germany: Springer-Verlag, 1990: 579-87. 